\title{
OS PENSIERI DE GIACOMO LEOPARDI EM PORTUGUÊS BRASILEIRO
}

\section{GIACOMO LEOPARDI'S PENSIERI IN BRAZILIAN PORTUGUESE}

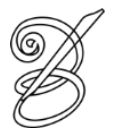 \\ Andréia GUERINI ${ }^{1}$ \\ Doutora em Literatura \\ Professora da Universidade Federal de Santa Catarina, CNPQ \\ Programa de Pós-Graduação em Estudos da Tradução (PGET) \\ Florianópolis, Santa Catarina, Brasil \\ andreia.guerini@gmail.com \\ Andréia RICONI ${ }^{2}$ \\ Doutoranda em Estudos da Tradução, CNPQ \\ Programa de Pós-Graduação em Estudos da Tradução (PGET) \\ Universidade Federal de Santa Catarina \\ Florianópolis, Santa Catarina, Brasil \\ andreiariconi@gmail.com
}

Resumo: Este artigo apresenta uma análise de alguns aspectos da tradução da única tradução brasileira de Pensieri, de Giacomo Leopardi, publicada em 1996. Em um primeiro momento, fazemos uma breve apresentação do autor e dos Pensieri no contexto de sua obra. Em seguida, analisamos a tradução feita por Vera Horn com base na teoria de Antoine Berman

Palavras-chave: Literatura italiana traduzida; Giacomo Leopardi; Pensieri.

Abstract: This article puts forward the analysis of some aspects concerning the only translation of Giacomo Leopardi's Pensieri (1837) into Brazilian Portuguese (1996). Firstly, we have proposed a brief presentation of Pensieri's author within the context of his production. Afterwards, we analyse Vera Horn's translation sustained by Antoine Berman's theory.

Keywords: Translated Italian Literature; Giacomo Leopardi; Pensieri.

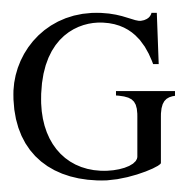
iacomo Leopardi (1798-1837) é um dos autores mais influentes da Literatura Italiana. Filólogo, ensaísta, prosador e poeta, Leopardi percorreu da literatura à política, da psicologia à filosofia, deixando uma vasta obra capaz de suscitar reflexões nos mais diferentes assuntos.

Mesmo tendo um grande volume de produções em prosa, Leopardi é mais comumente lembrado por ser o poeta dos Cantos $^{3}$. Ainda que suas obras mais reconhecidas em prosa, o Zibaldone di Pensieri e os Opúsculos Morais, também sejam bastante analisadas, a figura do Leopardi prosador e ensaísta, muitas vezes, fica escondida atrás da sombra do Leopardi poeta. Isso pode acontecer porque, de acordo com Giuseppe Sangirardi (2012, p. 41), "a hierarquia 
entre poesia e prosa na obra leopardiana encontrou importante sustentação na própria postura de Leopardi, que várias vezes declarou e mostrou uma afeição secreta e mais visceral por uma linguagem poética”. Sangirardi (idem) acredita, ainda, que essa opacidade da prosa em relação à poesia leopardiana, se deve pela “[...] indiscutível primazia do verso na tradição literária italiana até o século XIX”. Em contrapartida, quando se pensa na maneira como o autor vem sendo difundido também no exterior, é possível afirmar, como sustenta Guerini (2007, p. 25), que "um elemento que contribui para reforçar essa visão é o de que seus poemas são constantemente traduzidos e retraduzidos [...]”.

Dentre as produções em prosa de Giacomo Leopardi, estão os Pensieri ${ }^{4}$, publicados postumamente, em 1845, por Antonio Ranieri, amigo de Leopardi. Os Pensieri são, em sua maior parte, fruto de anotações desenvolvidas a partir de temáticas já presentes e (re)elaboradas do Zibaldone di Pensieri (1817-1832) e, segundo Giuseppe Bonghi (2001, p.1), "representam um conjunto de máximas morais sobre as quais, quase certamente entre 1835 e 1838, Leopardi havia trabalhado" ". Com o intuito de dar um ponto de partida e facilitar o acesso a esses escritos, Bonghi (Idem, p. 1/2) criou uma espécie de índice, no qual 38 sinaliza as temáticas centrais do texto e numera os pensamentos nos quais Leopardi se debruça sobre cada uma delas. Através desse índice já é possível verificar as temáticas mais recorrentes na reflexão leopardiana e constatar que o tema "homem" é o mais presente, seguido dos assuntos "juventude" e "malvadeza/maldade", que também, de certa maneira, se relacionam com a questão humana da primeira temática.

De acordo com Pietro Giordani, amigo e correspondente assíduo de Leopardi, originalmente o autor teria escrito mais de seiscentos pensamentos (BONGHI, 2001, p. 1) $)^{6}$, porém, a obra é constituída por apenas cento e onze pensamentos escolhidos. Como mencionado anteriormente, as temáticas que circundam o pensamento leopardiano são variadas, e estes cento e onze pensamentos selecionados marcam momentos de reflexão do autor acerca do homem e do mundo, sobre o modo como o próprio Leopardi via a si mesmo e os outros. De maneira geral, os Pensieri apresentam uma série de aforismos e máximas que refletem sobre as relações humanas e suas dinâmicas sociais (GUARRACINO, 1998, p. 136), que não se limitam a um período histórico e ainda hoje podem ser lidos em confronto com a sociedade atual.

A primeira e única versão até o presente momento dos Pensieri em português brasileiro foi publicada em 1996, pela tradutora Vera Horn, em uma coletânea intitulada Giacomo Leopardi: Poesia e Prosa, organizada por Marco Lucchesi, que reuniu, além de 
materiais de fortuna crítica, a tradução de outras produções importantes da prosa e da poesia leopardiana, como as Operette Morali, os Canti, alguns fragmentos escolhidos do Zibaldone di Pensieri, bem como cartas selecionadas do enorme epistolário. O que propomos para este artigo é uma análise da tradução brasileira de Pensieri, presente nessa coletânea, a fim de verificar as estratégias usadas pela tradutora, já que o texto leopardiano apresenta particularidades, como inversão da sintaxe, concisão, poeticidade, ou seja, tanto a forma quanto o conteúdo são intensamente trabalhados pelo autor de Recanati. Dada a complexidade do texto leopardiano, neste artigo nos deteremos, principalmente, em uma análise da tradução de elementos da estrutura sintática. Essa escolha se justifica pela complexidade da estrutura frasal que muitos dos escritos de Leopardi apresentam, sendo parte constituinte do estilo de escrita do autor. É importante ressaltar que, assim como cada tradução é uma leitura particular de determinada obra, a crítica de tradução também é, pois é abordada sob o viés das concepções de quem a critica. $\mathrm{O}$ que pretendemos aqui, portanto, é descrever algumas das estratégias utilizadas por Vera Horn, a fim de enriquecer a crítica sobre a obra, lançando-lhe um novo olhar.

A escrita de Leopardi se reveste de uma sintaxe muito peculiar ${ }^{7}$. Essa particularidade possivelmente se deva à ideia que o autor fazia dos autores e das obras modernas que, tomados pela afetação e pelo deslumbre da arte, acabavam por tornar artificiais seus escritos, racionalizando demais o ato de escrever. Leopardi acredita, em uma fase das suas reflexões, que a boa literatura só se dá pela mais perfeita imitação da natureza, pela espontaneidade, como faziam os antigos ${ }^{8}$. Portanto, para ele, “[...] deve parecer que o deleite, a viva representação etc. venha espontaneamente e sem que o poeta a tenha procurado [...]" (Zib., $52)^{10}$. Ademais, não podemos esquecer a distância temporal entre a escrita de os Pensieri e a tradução brasileira e, ao levar em conta esses aspectos iniciais, podemos dizer que, de modo geral, a estratégia da tradução de Vera Horn para os Pensieri foi a de privilegiar aspectos que dão um ar mais de domesticação do que estrangeirização. Isso talvez aconteça por querer "levar o autor ao leitor", pois o que fica mais evidente para o leitor bilíngue é a forma como Horn desmembra a estrutura frasal empregada por Leopardi, tornando o texto do autor italiano mais acessível e legível em nossa língua, como mostraremos abaixo. Essa estratégia foi descrita por Schleiermacher, em seu célebre ensaio intitulado "Sobre os diferentes métodos de tradução", de 1813 e no século XX por Lawrence Venuti. Já Antoine Berman (2012, p. 45) acredita que na tradução feita nesses moldes, os elementos estrangeiros do texto de partida aparecem aclimatados, tornando o texto familiar a ponto de parecer que foi escrito 
originalmente na língua de chegada. Porém, apesar de termos constatado essa característica no texto de Horn, é válido lembrar que mesmo que a opção da tradutora fosse percorrer o caminho oposto, isso não significa que a tradução não poderia comportar alguns elementos que Berman (2012, p. 40) chama de etnocêntricos - por trazerem tudo à cultura de chegada - e hipertextuais - por transformarem o texto em paródia ou pastiche de um “[...] outro texto já existente" (grifos do autor).

Para ilustrar os desmembramentos sintáticos feitos por Vera Horn, apresentaremos alguns exemplos dos 111 Pensamentos.

Nos Pensamentos XI e LIII Vera Horn "desconstrói" o texto leopardiano, reposicionando as frases, de modo que o texto em português tornou-se, de certa forma, mais "organizado" e legível, conforme podemos ver abaixo: Com o intuito de facilitar a compreensão, as frases foram numeradas no texto de partida e na tradução:

XI

(1)V'è qualche secolo che, (2) per tacere del resto, (3) nelle arti e nelle discipline (4) presume di rifar tutto, (5) perché nulla sa fare.

\section{LIII}

(1)Diceva Bione, (2)filosofo antico: è impossibile piacere alla moltitudine, se non diventando un pasticcio, o del vino dolce. (3) Ma questo impossibile, (4) durando lo stato sociale degli uomini, (5) sarà cercato sempre, anco da chi dica, ed anco da chi talvolta creda di non cercarlo(fazêlo): come, durando la nostra specie, i più conoscenti della condizione umana, persevereranno fino alla morte cercando felicità, e promettendosene.
(1)Há séculos que (4) presumem refazer tudo, (3) na arte e nas ciências, (2) para não falar do resto, (5) porque nada sabem fazer.

(1)Afirmava (2) o filósofo antigo (1)Bíon: "É impossível agradar a todos, se não tornando-se um pasticcio ou vinho doce". (4)Enquanto perdurar o estado social dos homens, (3)esse impossível (5)será sempre perseguido entre os que admitem e os que acaso não crêem fazê-lo; assim como, enquanto perdurar nossa espécie, os mais conhecedores da condição humana perseverarão até a morte em busca da felicidade, prometendo-a a si mesmos.

Uma das características de parte da escrita em prosa de Leopardi é a de o fluxo do pensamento aproximar-se da linguagem falada, ainda que muitas vezes erudita. É o que se poderia chamar, nas palavras de Tesi (2009, p. 122), de linguagem falada "literariamente reconstruída". Nota-se, ainda, mesmo quando se trata da prosa leopardiana, a presença de muitos elementos poéticos, revelados tanto em escolhas semânticas quanto na estrutura sintática sui generis. Segundo Dante Milano (1996, p. 137), “o pensamento de Leopardi é mais poético que todos os sentimentos, sensações e fantasias; mais autenticamente poéticos que os jorros de imagens e metáforas”. Essas duas características são visíveis nos fragmentos do texto de partida, mas nem sempre mantidos na tradução, especialmente no que tange à 
ordem das palavras na frase, pois quebra a estrutura "original" não apenas das palavras, mas do ritmo.

No Pensamento V, Vera Horn mantém as inversões, não seguindo, portanto, a ordem da sintaxe leopardiana:

(1)Nelle cose occulte vede meglio (2) sempre (3) il minor numero, (4) nelle palesi (5) il maggiore. È assurdo l'addurre quello che chiamano consenso delle genti nelle quistioni metafisiche: del qual consenso non si fa nessuna stima nelle cose fisiche, e sottoposte ai sensi; come per esempio nella quistione del movimento della terra, e in mille altre. Ed all'incontro è temerario, pericoloso, ed, al lungo andare, inutile, il contrastare all'opinione del maggior numero nelle materie civili [grifos nossos].
(3) A minoria (1) vê (2) sempre (1) melhor as coisas ocultas; (5) a maioria, (4) as evidentes. É absurdo aduzir o que chamam de consenso da maioria a respeito de questões metafísicas, para o qual não concorre nenhuma avaliação das coisas físicas e submetidas aos sentidos, como na questão do movimento da Terra e muitas outras. Contrariamente, é temerário, perigoso e, com o passar do tempo, inútil, contrariar a opinião da maioria a respeito de matérias civis [grifos nossos].

Além de algumas inversões, numeradas para facilitar a visualização, a tradução também suprime palavras e expressões, conforme destacamos em itálicos. Esse tipo de estratégia, conforme assinalado por Berman (2012, p. 68), pode evocar a ideia de "arborescência" que, segundo ele, é estrutura típica da grande prosa, sendo "diametralmente oposta à lógica linear do discurso enquanto discurso". Nesse sentido bermaniano, podemos dizer que o texto de Vera Horn é fruto de uma "racionalização", levando o texto de partida da “arborescência à linearidade" (Idem, p. 68). Quanto à supressão e acréscimo de termos, acreditamos que a tradutora possivelmente negociou seus acréscimos com algumas supressões, para garantir que o trecho em italiano e o trecho em português tivessem tamanhos similares, uma vez que a questão do "alongamento", tendencialmente presente em muitas traduções, pode ser um objeto da reflexão do tradutor e é tido por Berman como uma "deformação".

Outro exemplo em que a "arborescência" do texto de Leopardi foi tolhida e temos um caso de "alongamento" é o Pensamento LXIII, que diz o seguinte:

Il concetto che l'artefice ha dell'arte sua o lo scienziato della sua scienza, suol essere grande in proporzione contraria al concetto ch'egli ha del proprio valore nella medesima [grifos nossos].
$\mathrm{O}$ conceito que o artista atribui à sua arte ou o cientista, à sua própria ciência, costuma ser elevado em proporção contrária ao conceito que atribui a si mesmo no contexto daquela arte ou daquela ciência [grifos nossos]. 
Nesta passagem, ao contrário da anterior, Vera Horn parece não ter demonstrado preocupação quanto a alterar significativamente o número de palavras. Aparentemente, a tradutora agiu "clarificando" o texto leopardiano, na tentativa de esmiuçar o "sentido" da frase. Prova disso é o modo como optou por verter a passagem sublinhada, que em italiano, traduzida "literalmente" seria "tem do próprio valor". Como Horn parece ter julgado que apenas dizer "tem do próprio valor na mesma" (que seria a tradução da parte grifada em itálico), não seria suficiente, retomou as palavras arte e ciência para que o leitor fosse capaz de se situar em relação ao que Leopardi estava fazendo referência.

Mesmo não sendo o foco principal dessa análise, acreditamos ser válido demonstrar como algumas escolhas semânticas também podem mudar o tom do texto. Retomando a ideia de um Leopardi que pensa e escreve poeticamente, temos o Pensamento IX:

Chi contro all'opinione d'altri ha predetto il successo di una cosa nel modo che poi segue, non si pensi che i suoi contraddittori, veduto il fatto, gli dieno ragione, e lo chiamino più savio o più intendente di loro: perché o negheranno il fatto, o la 42 predizione, o allegheranno che questa e quello differiscano nelle circostanze, o in qualunque modo troveranno cause per le quali si sforzeranno di persuadere a se stessi e agli altri che l'opinione loro fu retta, e la contraria torta [grifos nossos].
Quem, contra a opinião alheia, previu o sucesso de algo que ao cabo se realizou, não creia que seus opositores, conhecido o fato, lhe dêem razão ou que lhe chamem mais sábio ou mais perspicaz; porque negarão o fato ou a previsão, ou alegarão mesmo que um e outra não se confirmam pelas circunstâncias, ou de alguma forma encontrarão meios de persuadir a si mesmos e aos outros de que sua opinião era correta e a contrária, enganosa [grifos nossos].

Além da supressão, assinalada em itálico, há os termos marcados em negrito, tanto no texto de partida quanto na tradução. Leopardi usou metaforicamente as palavras "retta" e "torta" para falar das opiniões (a própria e a dos outros, respectivamente), enquanto na tradução, as palavras "correta" e "enganosa" não são capazes de trazer a mesma ideia de contraposição. Temos aqui o que Berman chama de "empobrecimento qualitativo", no qual a riqueza sonora e significante dos termos e expressões do texto de partida se perde em escolhas que, apesar de demonstrarem o sentido, não demonstram a "verdade" contida naqueles termos e expressões originalmente empregados, não remetendo à sua "corporeidade icônica" (BERMAN, 2012, p. 75).

Embora a tradutora de os Pensieri tenha optado por "levar o autor ao leitor", "domesticando" o texto, e não tenha mantido aspectos da escrita leopardiana que consideramos importantes para manter o estilo do autor, como demonstrado com os exemplos acima mencionados, concluímos que essa sua estratégia não invalida o complexo trabalho de 
verter os Pensieri para o português brasileiro, mas sim, contribui para adentrarmos na densa selva leopardiana.

\section{REFERÊNCIAS BIBLIOGRÁFICAS}

BERMAN, Antoine. A tradução e a letra ou o albergue do longínquo. Tradução de Marie Hélène Catherine Torres, Mauri Furlan e Andréia Guerini. Tubarão: Copiart/Florianópolis: PGET, 2012.

BERMAN, Antoine. A prova do estrangeiro. Tradução de Maria Emília Pereira Chanut. Bauru: EDUSC, 2002.

BONGHI, Giuseppe. Biografia di Giacomo Leopardi. Biblioteca dei Classici Italiani: Ed. 2004. [disponível em: http://www.classicitaliani.it/bonghiG/bonghi_biografia_Leopardi.htm]

GUARRACINO, Vincenzo. Guida alla lettura di Leopardi. Milano: Mondadori, 1998.

GUERINI, Andréia. Gênero e Tradução no Zibaldone de Leopardi. São Paulo: Edusp, 2007.

LEFEVERE, André. Tradução, reescrita e manipulação da fama literária. Tradução de Claudia Matos Seligmann. Bauru: Edusp, 2007.

LEOPARDI, Giacomo. Pensieri. In: Tutte le opere, vol. I. Firenze: Sansoni Editore, 1969. [disponível em: http://www.bibliotecaitaliana.it/indice/visualizza_testo_html/bibit000436]

Poesia e prosa. LUCCHESI, Marco (org). Traduções: Affonso Félix de Sousa, Alexei Bueno et al. Rio de Janeiro: Nova Aguilar, 1996.

Milano: Garzanti, 1991.

Zibaldone di Pensieri. A cura di Giuseppe Pacella. V. I, II e III.

MARAZZINI, Claudio. Breve storia della lingua italiana. Bologna: il Mulino, 2004.

MIGLIORINI, Bruno. Storia della lingua italiana. Milano: Bompiani, 1995, III edizione.

MILANO, Dante. Leopardi. In: Poesia e prosa. LUCCHESI, Marco (org). Traduções: Affonso Félix de Sousa, Alexei Bueno et al. Rio de Janeiro: Nova Aguilar, 1996.

MOYSÉS, Tânia Mara. A língua bilíngue do tempo nas estratégias de tradução do Zibaldone de Leopardi. Revista Appunti Leopardiani: Ed. 2012/3. [Disponível em: http://www.appuntileopardiani.cce.ufsc.br/edition03/artigosphp/a_linha_bilingue_do_tempo.p $\mathrm{hp}]$

RICOEUR, Paul. Sobre a Tradução. Belo Horizonte: Editora UFMG, 2011. Tradução: Patrícia Lavelle. 
SANGIRARDI, Giovani. Perfil de Leopardi prosador. Tradução de Andréia Riconi e Andréia Guerini. Revista Appunti Leopardiani: Ed. 2/2012. [disponível em: http://www.appuntileopardiani.cce.ufsc.br/edition04/artigos/perfil-de-Leopardi-prosador.php]

SCHLEIERMACHER, Friedrich. "Sobre os diferentes métodos de tradução". Tradução de. Margarete von MühlenPoll. In: Clássicos da teoria da tradução. Werner Heidermann (org.). V.I. Antologia Bilíngüe. Florianópolis: UFSC, 2001.

SNELL-HORNBY, Mary. A "estrangeirização de Venuti: o legado de Friedrich Schleiermacher aos Estudos da Tradução?. In: Pandaemonium Germanicum, v. 15, n. 19, 2012. Texto disponível em http://www.revistas.usp.br/pg/article/view/39802.

TESI, Riccardo. Storia dell'Italiano: La lingua moderna e contemporanea. Bologna: Zanichelli editore, 2009.

TESI, Riccardo. Enciclopedia dell'italiano. Roma: Istituto della Enciclopedia Italiana, 2010.

${ }^{1}$ Lattes Andréia Guerini. Disponível em: http://lattes.cnpq.br/1962473391601725

${ }^{2}$ Lattes Andréia Riconi. Disponível em: http://lattes.cnpq.br/7684121815474758

3 Sobre este aspecto, ver artigo Sangirardi, Giuseppe. "Perfil de Leopardi prosador" in http://www.appuntileopardiani.cce.ufsc.br/edition04/artigos/perfil-de-Leopardi-prosador.php, acesso em 20/09/2014

4 A edição dos Pensieri que utilizamos é a da Biblioteca Italiana, disponível em: http://www.bibliotecaitaliana.it/indice/visualizza_testo_html/bibit000436

${ }^{5}$ Quando não indicadas, as traduções são de nossa autoria.

${ }^{6}$ Segundo Giuseppe Bonghi, Pietro Giordani afirma, em uma carta que escreveu a Prospero Viani, em 1845, que Antonio Ranieri lhe havia falado que existiam outros 600 pensamentos.

${ }^{7}$ A este propósito, cfr. R. TESI, Riccardo. Enciclopedia dell'italiano. Roma: Istituto della Enciclopedia italiana, 2010, pp. $774 \quad-\quad 777 . \quad$ Disponível em: http://www.treccani.it/enciclopedia/giacomoleopardi_(Enciclopedia_dell'Italiano)/

${ }^{8}$ A este propósito cfr. LEOPARDI, Giacomo. Zibaldone di pensieri. A cura di Giuseppe Pacella. Milano: Garzanti, 1991, aut. 3, 4 e 5.

9 Tradução de Andréia Guerini, Anna Palma e Tânia Mara Moysés.

${ }^{10}$ A edição do Zibaldone di Pensieri que tomamos como referência é a edição organizada por Giuseppe Pacella. LEOPARDI, Giacomo. Zibaldone di pensieri. A cura di Giuseppe Pacella. Milano: Garzanti, 1991. v. I, II, III.

ACEITO EM: 01/12/2014

RECEBIDO EM: 20/07/2015 